\title{
Low-Cost SVM-DTC Strategy of Induction Machine Drives Using Single DC-link Current Sensor
}

\author{
Wei Wang*, Ming Cheng*, Wei Hua*, Shichuan Ding*, Ying Zhu*, Wenxiang Zhao**
}

\begin{abstract}
In conventional direct torque control (DTC) using space-vector modulation (SVM) of induction machine (IM) drives, at least three current sensors are needed. In this paper, a low-cost SVM-DTC strategy is proposed, in which only a single current sensor is used. The position of the voltage space vector is divided into two areas: effective and noneffective area. If it is located in the non-effective area, the voltage space vector will be shifted into the effective area with minimum distortion. Further, the switching frequency remains constant. The simulation is carried out on a MATLAB/Simulink platform and the simulated results verify the effectiveness of the proposed strategy.
\end{abstract}

Keywords: Direct torque control (DTC), Single current sensor, Induction machines.

\section{Introduction}

Direct torque control (DTC) was proposed in the mid 1980s [1]-[2]. Due to the advantages of its simple structure, quick torque response and robustness, DTC has received a lot of attention in literature [3]-[8] and has been widely used in fields requiring fast torque response, such as electric traction drives of rail transit. In nature, DTC accomplishes the closed-loop control of the stator flux magnitude and the electromagnetic torque without current regulators and rotor position information. As is known, the conventional DTC needs the signals of phase currents and dc-link voltage, together with the states of the inverter switches. In other words, two current sensors and one voltage sensor are necessary to attain the realization of the conventional DTC. Additionally, one extra current sensor is always mounted in the dc-link for over current protection. The conventional DTC scheme is shown in Fig. 1(a). However, the use of sensors tends to degrade the reliability of the drive system; on the other hand, the cost reduction is one of various efforts for widening the applications of motor drives. Therefore, many efforts are made to minimize the number of current sensors to control electric machines. In [9]-[13], several current-sensorless methods are presented. Although the cost of corresponding drive systems are reduced significantly, these current-sensorless

\footnotetext{
* School of Electrical Engineering, Southeast University, China. (mch eng@seu.edu.cn)

** School of Electrical and Information Engineering, Jiangsu University, China

Received 31 September 2011; Accepted 17 July 2012
}

methods are based on accurate electric machine models, which weaken the robustness of corresponding drive systems. Since the dc-link current reflects one of the three phase currents if the inverter uses the active voltage space vectors, several single-current-based methods of motor drives are presented [14]-[18], and the most typical drive system is shown in Fig. 1(b). In [15], a DTC scheme using a single dc-link current sensor is introduced. However, the scheme works well only when the switching frequency of the inverter is high. In [16], another single-current-based DTC scheme is presented: firstly, phase currents are estimated by the model of an induction motor; then, the estimated phase currents are adjusted by the sensed dc-link current. In [18], the space vector PWM algorithm of the permanent magnet synchronous motor servo drives is accomplished by a single dc-link current sensor.

The purpose of this paper is to propose a low-cost but high-performance space-vector modulation-direct torque control (SVM-DTC) strategy using a single dc-link current sensor. In the proposed strategy, the position of the voltage space vector is divided into two areas: effective and noneffective area. If it is located in the non-effective area, the voltage space vector will be simply shifted to the effective area. In the shifting procedure, the switching frequency of the inverter remains constant. Simulated results, based on MATLAB/Simulink, will be presented to demonstrate the validity of the proposed strategy. In this paper, the analysis is focused on an induction machine (IM) while other machine types can be analyzed through a similar method. 


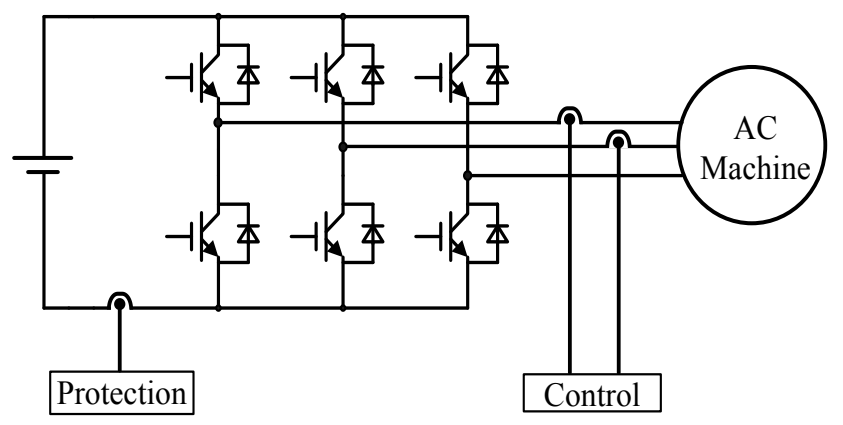

(a)

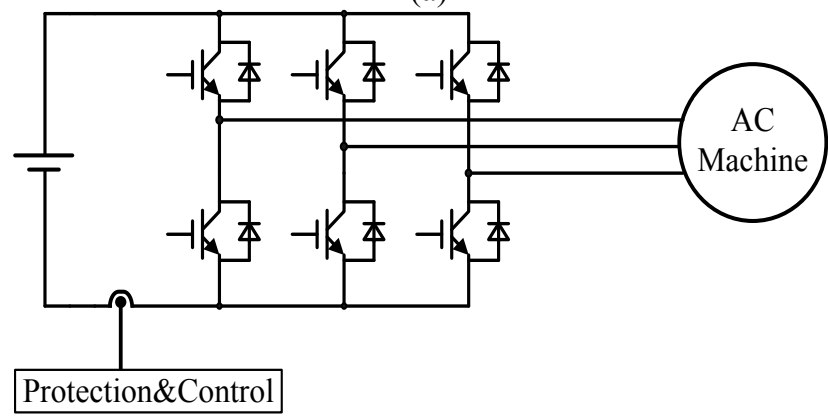

(b)

Fig. 1. Three phase AC machine drive. (a) Using three current sensors. (b) Using single current sensor.

\section{Proposed Strategy}

\subsection{Basic Concept of SVM-DTC}

In this paper, stator vectors are obtained by the coordinate transformation from the three-phase stationary coordinate $a b c$ to the two-axis stationary coordinate $\alpha-\beta$ with the axis aligned along the Phase-A of the stator.

Current Vector Calculator computes $\bar{i}_{s}$ by

$$
\bar{i}_{s}=\frac{2}{3}\left(i_{a s}+i_{b s} e^{j \frac{2 \pi}{3}}+i_{c s} e^{j \frac{4 \pi}{3}}\right)
$$

where $i_{a s}$ and $i_{b s}$ are the sensed Phase-A and Phase-B current, and Phase-C current $i_{c s}$ is determined by

$$
i_{c s}=-\left(i_{a s}+i_{b s}\right)
$$

where the stator windings are connected in the "Y" shape.

Voltage Vector Calculator computes $\bar{u}_{S}$ by

$$
\bar{u}_{s}=\frac{2}{3} u_{d c}\left(s_{a}+s_{b} e^{j \frac{2 \pi}{3}}+s_{c} e^{j \frac{4 \pi}{3}}\right)
$$

where $u_{d c}$ is the sensed dc-link voltage, and $s_{a}, s_{b}, s_{c}$ are the states of the upper switches of the inverter ( $s=1$ means switch closed and $s=0$ means switch open).

Flux\&Torque Estimator aims to acquire the stator flux vector $\bar{\psi}_{s}$ and the electromagnetic torque $T_{e} \cdot \bar{\psi}_{s}$ is given by

$$
\bar{\psi}_{s}=\int\left(\bar{u}_{s}-\bar{i}_{s} R_{s}\right) d t
$$

where $R_{s}$ is the stator resistance. The stator flux magnitude $\psi_{s}$ and the electromagnetic torque $T_{e}$ can be calculated by

$$
\begin{gathered}
\psi_{s}=\sqrt{\psi_{\alpha s}^{2}+\psi_{\beta s}^{2}} \\
T_{e}=\frac{3}{2} p_{n}\left(\psi_{\alpha s} i_{\beta s}-\psi_{\beta s} i_{\alpha s}\right)
\end{gathered}
$$

where $p_{n}$ is pole pairs of IM, $\bar{\psi}_{s}=\psi_{\alpha s}+j \psi_{\beta s}$, $\bar{i}_{s}=i_{\alpha s}+j i_{\beta s}$.

\subsection{Basic Concept of Voltage Space Vector}

There are eight voltage space vectors, including six active voltage space vectors $\left(\bar{U}_{1}-\bar{U}_{6}\right)$ and two zero voltage space vectors $\left(\bar{U}_{0}, \bar{U}_{7}\right)$. They are labeled with the switch states $\left(s_{a}, s_{b}, s_{c}\right)$ and listed in Table 1 . The distribution of voltage space vectors is illustrated in Fig. 2.

Table 1. Voltage space vectors

\begin{tabular}{|c|c|c|c|c|c|c|c|c|}
\hline $\mathrm{SV}$ & $\bar{U}_{0}$ & $\bar{U}_{1}$ & $\bar{U}_{2}$ & $\bar{U}_{3}$ & $\bar{U}_{4}$ & $\bar{U}_{5}$ & $\bar{U}_{6}$ & $\bar{U}_{7}$ \\
\hline$s_{a} s_{b} s_{c}$ & 000 & 100 & 110 & 010 & 011 & 001 & 101 & 111 \\
\hline
\end{tabular}

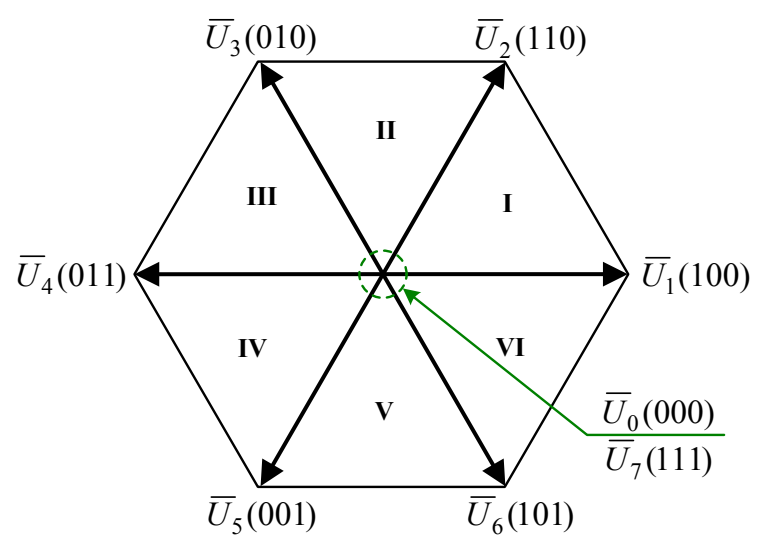

Fig. 2. Distribution diagram of both voltage space vectors and sectors

(6) can be rewritten as

$$
T_{e}=\frac{3}{2} p_{n} \psi_{s} i_{s} \sin \delta
$$

where $\delta$ is the angle between $\bar{\psi}_{s}$ and $\bar{i}_{s}$. Because the stator flux magnitude $\psi_{s}$ is kept nearly constant and the stator current magnitude $i_{s}$ can not be suddenly changed, quick response of the electromagnetic torque only can be implemented by changing $\delta$. In fact, the change of $\delta$ 
can be achieved by rotating the stator flux, as is shown in Fig. 3.

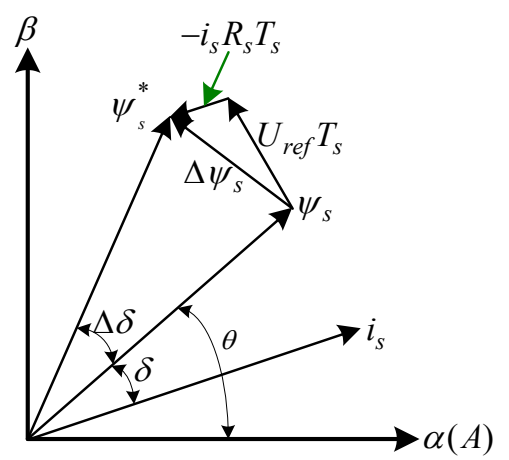

Fig. 3. Diagram of the rotation of stator flux

From Fig. 3, the variation of the stator flux $\Delta \psi_{s}$ can be derived by

$$
\left\{\begin{array}{l}
\Delta \psi_{\alpha s}=\psi_{s}^{*} \cos (\theta+\Delta \delta)-\psi_{s} \cos \theta \\
\Delta \psi_{\beta S}=\psi_{s}^{*} \sin (\theta+\Delta \delta)-\psi_{s} \sin \theta
\end{array}\right.
$$

where $\psi_{s}^{*}, \theta$ and $\Delta \delta$ is the reference of the stator flux magnitude, the phase angle of $\bar{\psi}_{s}$ and the variation of $\delta$, respectively; $\Delta \psi_{s}=\Delta \psi_{\alpha s}+j \Delta \psi_{\beta s}$.

By (4) and (8), the reference of the stator voltage $\bar{U}_{r e f}$ is calculated by

$$
\begin{gathered}
\left\{\begin{array}{l}
u_{\alpha s}=\left(\Delta \psi_{\alpha s}+R_{s} i_{\alpha s}\right) / T_{s} \\
u_{\beta s}=\left(\Delta \psi_{\beta s}+R_{s} i_{\beta s}\right) / T_{s}
\end{array}\right. \\
\left\{\begin{array}{l}
U_{r e f}=\sqrt{\left(u_{\alpha s}\right)^{2}+\left(u_{\beta s}\right)^{2}} \\
\gamma=\angle \bar{U}_{r e f}
\end{array}\right.
\end{gathered}
$$

where $T_{s}$ is the switching period, $\gamma$ is the phase angle of $\bar{U}_{r e f}$. In this paper, six sectors are defined as following

$$
\left\{\begin{array}{l}
\text { SectorI: } \quad 0<=\theta<\pi / 3 \\
\text { SectorII: } \quad \pi / 3<=\theta<2 \pi / 3 \\
\text { SectorIII: } \quad 2 \pi / 3<=\theta<\pi \\
\text { SectorIV: } \quad \pi<=\theta<4 \pi / 3 \\
\text { SectorV: } \quad 4 \pi / 3<=\theta<5 \pi / 3 \\
\text { SectorVI: } \quad 5 \pi / 3<=\theta<2 \pi
\end{array}\right.
$$

which is shown in Fig. 2. $\bar{U}_{r e f}$ is located in one sector determined by $\gamma$. Based on the theory of space vector, $\bar{U}_{r e f}$ can be synthesized by two nearest active voltage space vectors $\left(\bar{U}_{k}, \bar{U}_{k+1}\right)$ and two zero voltage space vectors $\left(\bar{U}_{0}, \bar{U}_{7}\right)$, as illustrated in Fig. 4.
And the acting times of SVs are calculated by

$$
\begin{gathered}
\bar{U}_{r e f}=\left(T_{k} \bar{U}_{k}+T_{k+1} \bar{U}_{k+1}\right) / T_{s} \\
\left\{\begin{array}{l}
T_{k}=\sqrt{3} T_{s} U_{r e f} \sin \left(60^{\circ}-\varphi\right) / u_{d c} \\
T_{k+1}=\sqrt{3} T_{s} U_{r e f} \sin \varphi / u_{d c} \\
T_{0}=T_{s}-T_{k}-T_{k+1}
\end{array}\right.
\end{gathered}
$$

where $\varphi$ is the modulus after division of $\gamma$ and $60^{\circ}$; $T_{k}, T_{k+1}, T_{0}$ are the acting time of $\bar{U}_{k}, \bar{U}_{k+1}$, zero voltage space vectors, respectively. The switch states are optimized to be center symmetric and are illustrated in Fig. 5.

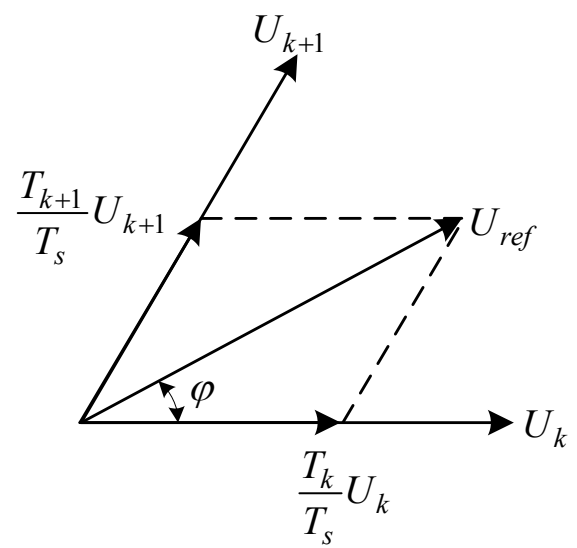

Fig. 4. Synthesization of $\bar{U}_{r e f}$.

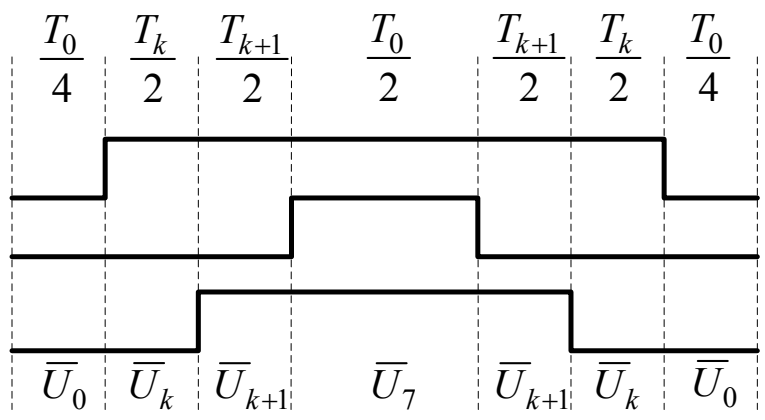

Fig. 5. Output timing of switch states

\subsection{Using a single current sensor}

When the inverter applies an active voltage space vector to the IM, one stator phase is connected in series to the dclink rail of the inverter, either to the positive or to the negative polarity, whereas the other two phases are connected in parallel to the opposite polarity. The in-series 
phase can be easily identified from the states of the upper switches of the inverter, and the current flowing in this phase is either equal or opposite to the dc-link current as illustrated in Table 2.

Table 2. DC-link in-series stator phase current versus space vectors

\begin{tabular}{|c|c|c|c|c|c|}
\hline $\bar{U}_{1}$ & $\bar{U}_{2}$ & $\bar{U}_{3}$ & $\bar{U}_{4}$ & $\bar{U}_{5}$ & $\bar{U}_{6}$ \\
\hline$i_{a s}=i_{d c}$ & $i_{c s}=-i_{d c}$ & $i_{b s}=i_{d c}$ & $i_{a s}=-i_{d c}$ & $i_{c s}=i_{d c}$ & $i_{b s}=-i_{d c}$ \\
\hline
\end{tabular}

However, the selected active voltage space vector must be used long enough to ensure a proper sampling of the dclink current. The minimum acting time $T_{\min 1}$ is given as

$$
T_{\min 1}=T_{\text {dead }}+T_{\text {set }}+T_{A D}
$$

where $T_{\text {dead }}, T_{\text {set }}$ and $T_{A D}$ are the dead time of the inverter, the setup time of the dc-link current and the converting time of the A/D converter, respectively. Besides, to keep the switching frequency constant, $T_{0}$ has a minimum value defined as $T_{\min 2}$. Therefore, $\bar{U}_{r e f}$ is limited by

$$
\left\{\begin{array}{l}
T_{k}>2 T_{\min 1} \\
T_{k+1}>2 T_{\min 1} \\
T_{0}>T_{\min 2}
\end{array}\right.
$$

And the effective area of $\bar{U}_{r e f}$ is represented by the white areas in Fig. 6.

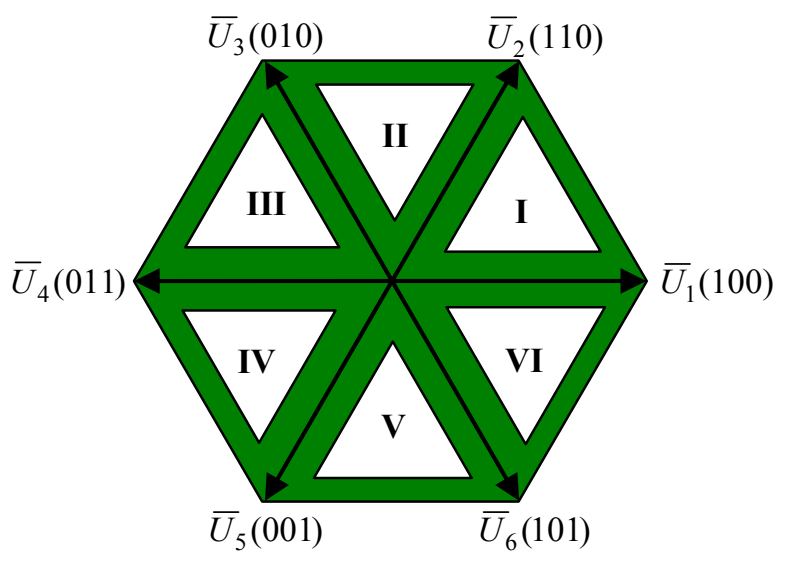

Fig. 6. Effective area (white) and non-effective area(green).

If it is in the non-effective area represented by the shaded area in Fig. 6, $\bar{U}_{r e f}$ is shifted into the effective area by Fig. 7.

\section{Implementation}

For the validation of the proposed DTC scheme, a s imulation platform based on Matlab/Simulink was devel oped, as is shown in Fig. 8. A $150 \mathrm{~V}$ DC source is su pplied and an IGBT-inverter-fed IM is used. The input s of the DTC controller includes: 1) sample values of the signals coming from the sensors of current and vol tage in the dc-link; 2) feedback value of the motor sp eed. As well, the switch states are exported from the DTC controller to drive the inverter. Parameters of the simulation platform are listed in TABLE IV.

Table 3. Parameters of IM

\begin{tabular}{|c|c|}
\hline Parameter & Value \\
\hline Rated power $P_{e}$ & $5.5 \mathrm{~kW}$ \\
\hline Rated phase voltage $V_{r m s}$ & $220 \mathrm{~V}$ \\
\hline Rated rotation speed $N_{n}$ & $1450 \mathrm{r} / \mathrm{mim}$ \\
\hline Stator resistance $R_{l}$ & $0.628 \Omega$ \\
\hline Rotor resistance $R_{2}$ & $1.192 \Omega$ \\
\hline Stator self-inductance $L_{11}$ & $5.668 \mathrm{mH}$ \\
\hline Rotor self-inductance $L_{22}$ & $5.668 \mathrm{mH}$ \\
\hline Mutual inductance $L_{m}$ & $163.9 \mathrm{mH}$ \\
\hline Pole pairs $p_{n}$ & 2 \\
\hline Inertia $J$ & $0.2674 \mathrm{~kg} \cdot \mathrm{m}^{2}$ \\
\hline Friction factor $\delta$ & $0.0016 \mathrm{~N} \cdot \mathrm{m} \cdot \mathrm{s}$ \\
\hline
\end{tabular}

Table 4. Parameters of simulation platform

\begin{tabular}{|c|c|}
\hline Parameter & Value \\
\hline Dead time & $5 \mu \mathrm{s}$ \\
\hline Switching frequency & $20 \mathrm{kHz}$ \\
\hline Sampling frequency & $20 \mathrm{kHz}$ \\
\hline
\end{tabular}

A test has been executed on the platform to evaluate the steady and transient performances of the proposed DTC scheme. In the test, the stator flux magnitude of the IM is controlled at $0.5 \mathrm{~Wb}$ and the motor is operated at $500 \mathrm{r} / \mathrm{min}$. In $t=3.5 \mathrm{~s}$, a torque disturbance of $-10 \mathrm{Nm}$ is added and kept at $0.01 \mathrm{~s}$. The simulated results of tests are illustrated in Fig. 9 and Fig. 10 respectively.

No matter whether the process is steady or transient, the estimated Phase-A current $i_{a s}^{e}$ always matches the measured Phase-A current $i_{a s}^{m}$ well, seen in Fig. 9(a) and Fig. 10(a). Both the steady-state and transient torques are well controlled and reported in Fig. 9(b) and Fig. 10(b). Besides this, the stator flux is also well controlled, as shown in Fig. 9(c) and Fig. 10(c) 


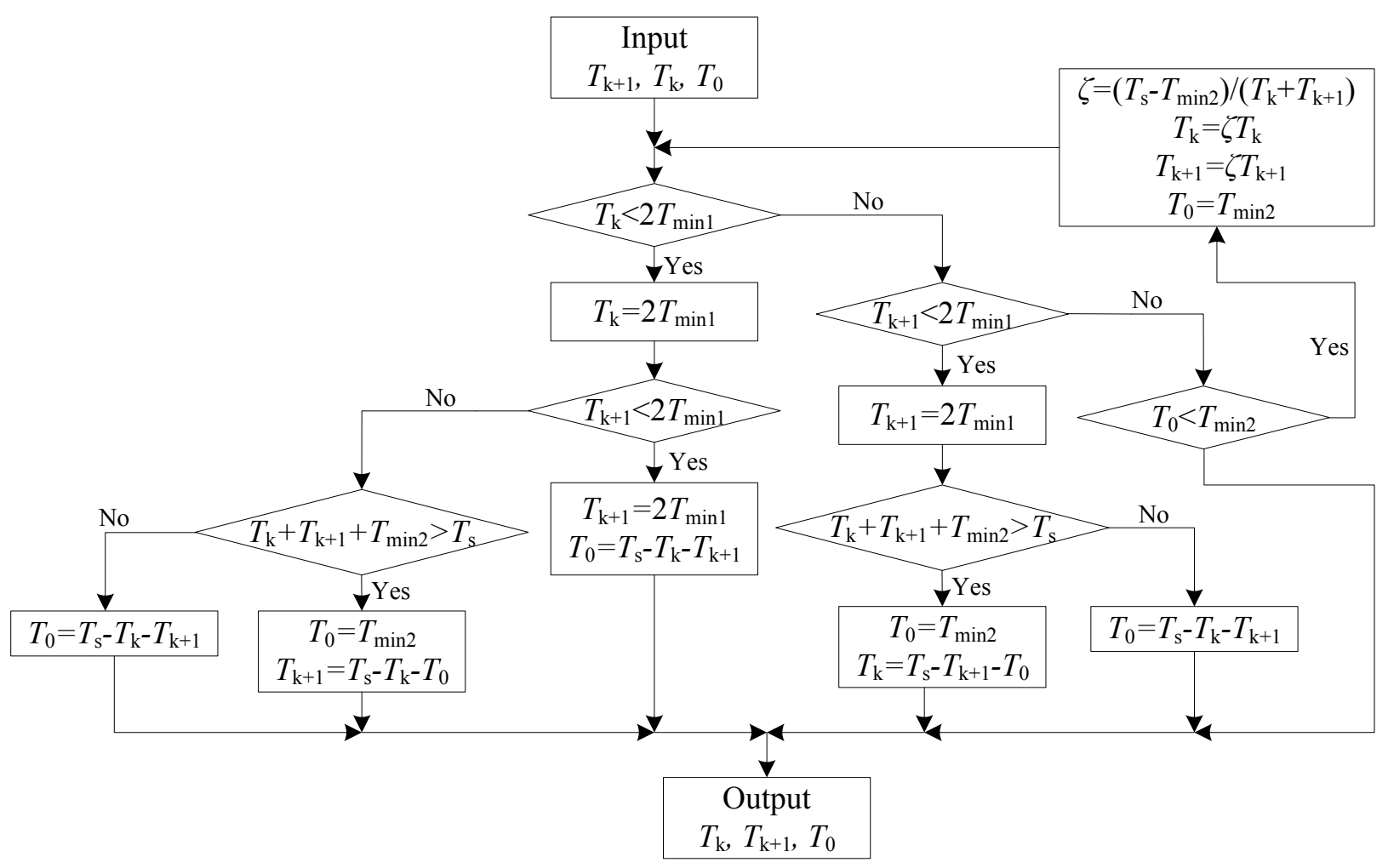

Fig. 7. Flow chart of shifting algorithm

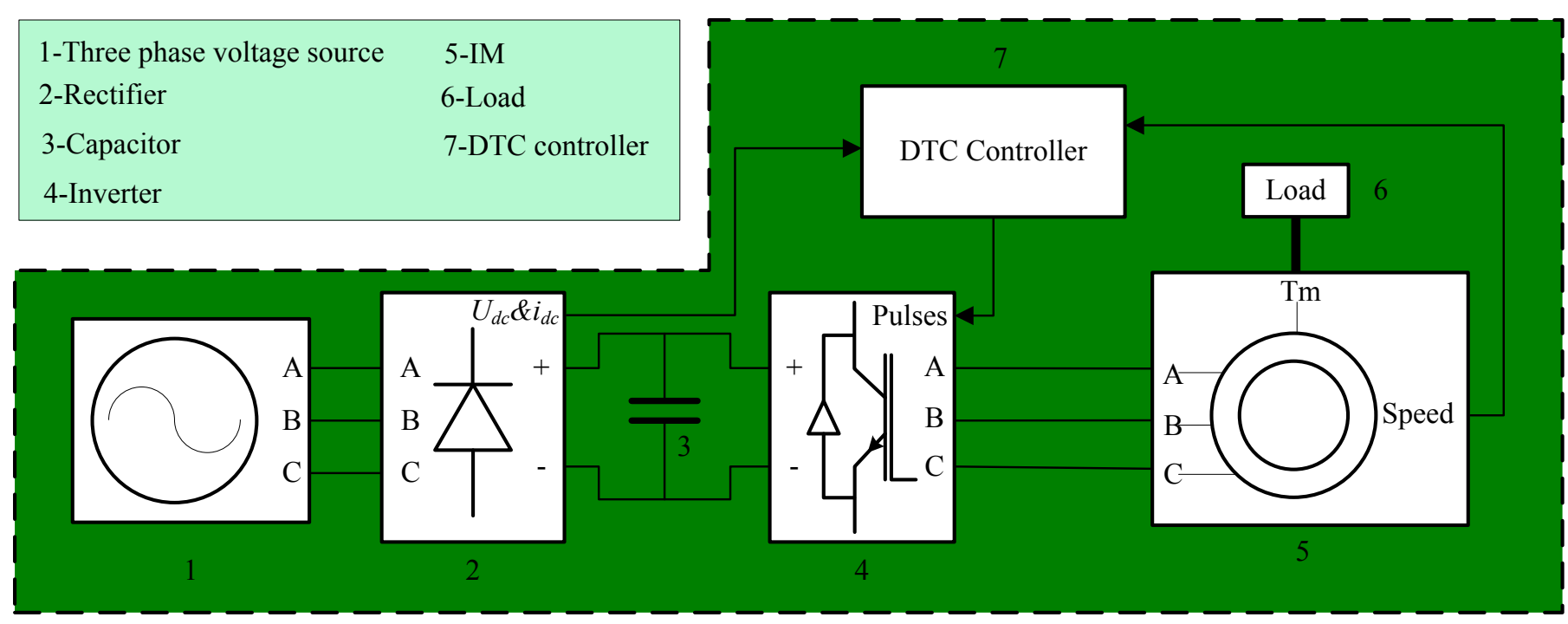

Fig. 8. Block diagram of simulation platform. 


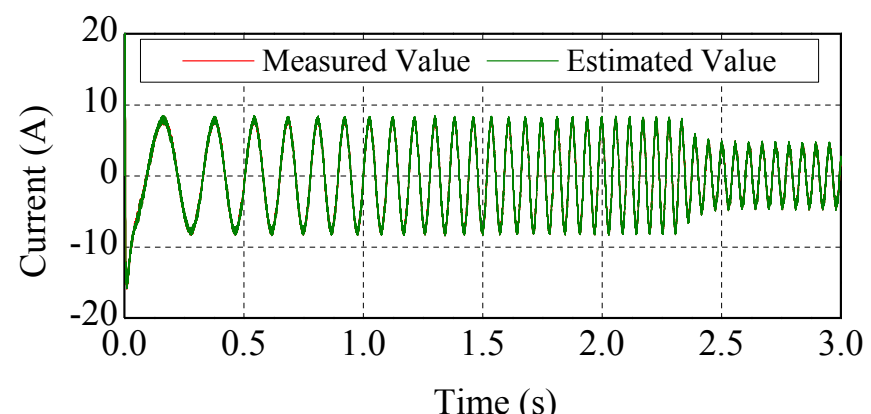

(a)

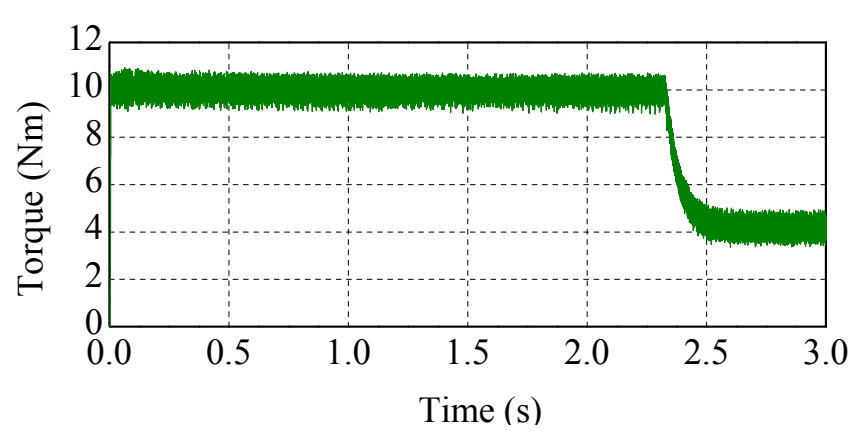

(b)

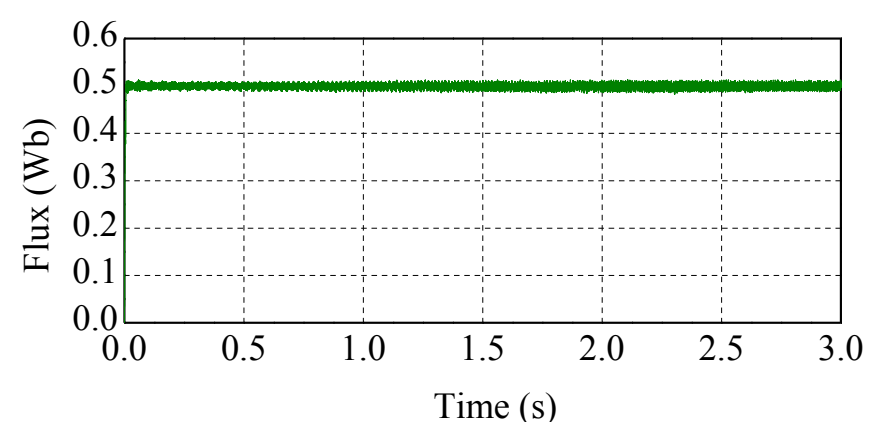

(c)

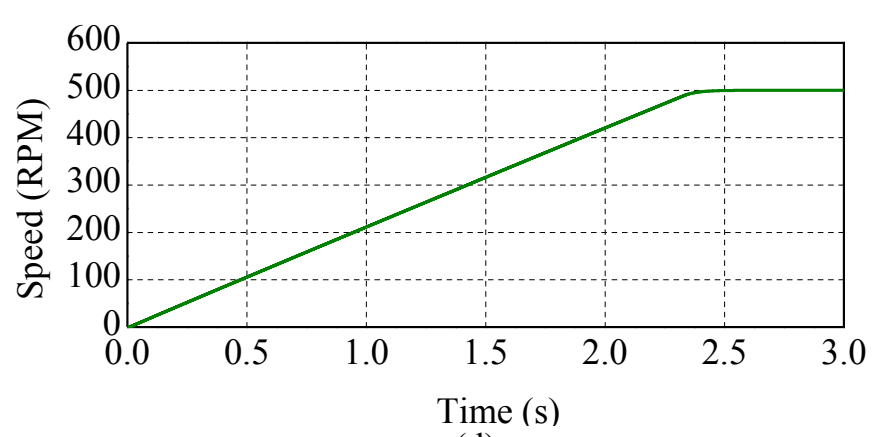

(d)

Fig. 9. Steady performances. (a) Current; (b) Electromagnetic torque; (c) Stator flux; (d) Speed.

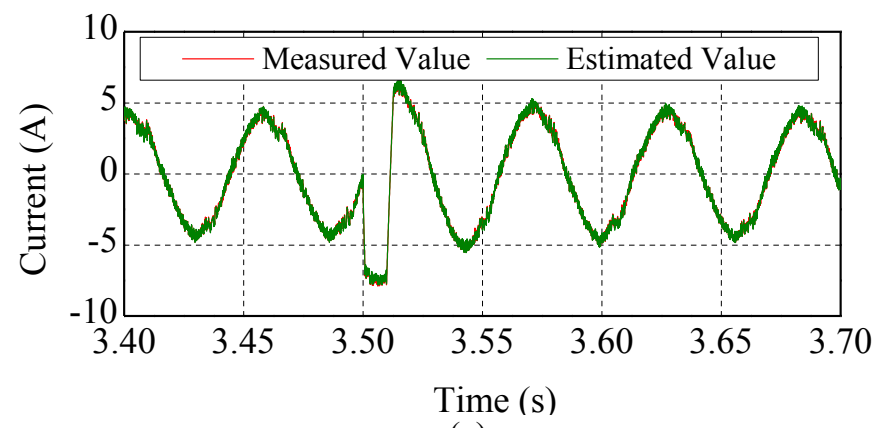

(a)

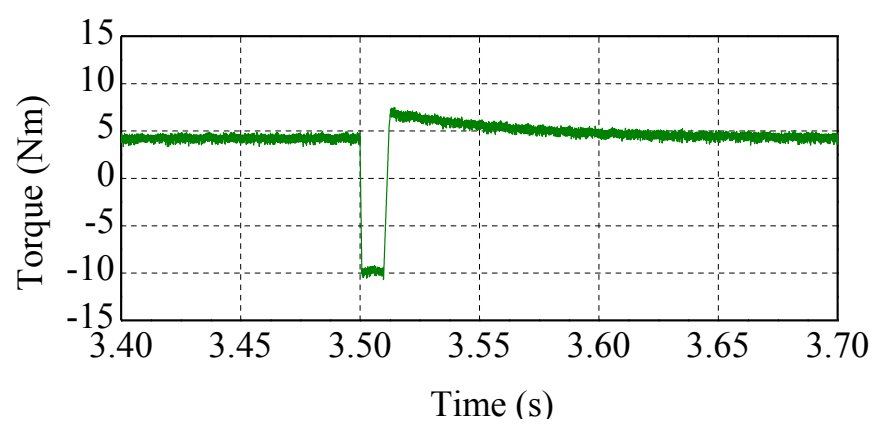

(b)

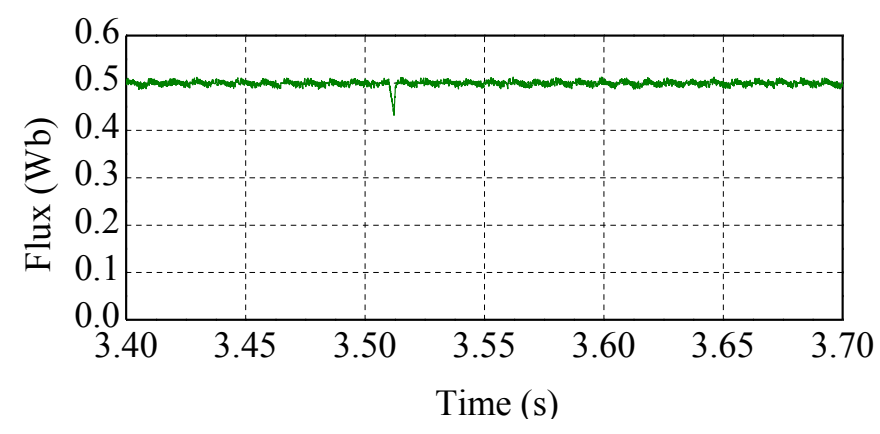

(c)

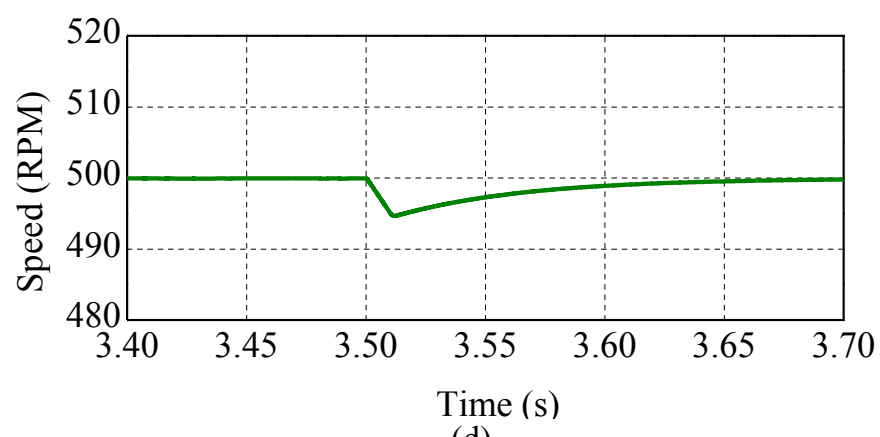

(d)

Fig.10.Transient performances. (a) Current; (b) Electromagnetic torque; (c) Stator flux; (d) Speed. 


\section{Conclusion}

In this paper, a low-cost SVM-DTC strategy of IM drives with a single current sensor has been proposed. A simple shifting scheme has been developed to ensure that all voltage space vectors can be shifted into an effective area with minimum distortion. Additionally, the switching frequency remains constant. The steady-state and transient performances of the motor drive have been analyzed by simulation and the results confirm the effectiveness of the proposed strategy.

\section{Acknowledgements}

This work was supported by the Program Sponsored for Scientific Innovation Research of College Graduate in Jiangsu Province, China (Project: CXZZ_0149).

\section{References}

[1] I. Takahashi and T. Noguchi, "A new quick-response and high-efficiency control strategy of an induction motor," IEEE Trans. Ind. Appl., vol. IA-22, pp. 820-827, Sep./Oct. 1986.

[2] M. Depenbrock, "Direct self-control (DSC) of inverter-fed induction machine," IEEE Trans. Power Electron., vol. 3, pp. 420-429, Oct. 1988.

[3] M. Hajian, J. Soltani, G. A. Markadeh, and S. Hosseinnia, "Adaptive nonlinear direct torque control of sensorless IM drives with efficiency optimization," IEEE Trans. Ind. Electron., vol. 57, pp. 975-985, Mar. 2010.

[4] K. K. Shyu, J. K. Lin, V. T. Pham, M. J. Yang, and T. W. Wang, "Global minimum torque ripple design for direct torque control of induction motor drives," IEEE Trans. Ind. Electron., vol. 57, pp. 3148-3156, 2010.

[5] J. Beerten, J. Verveckken, and J. Driesen, "Predictive direct torque control for flux and torque ripple reduction," IEEE Trans. Ind. Electron., vol. 57, pp. 404-412, 2010.

[6] Y. Zhang, J. G. Zhu, W. Xu, and Y. Guo, "A simple method to reduce torque ripple in direct torque controlled permanent magnet synchronous motor by using vectors with variable amplitude and angle," IEEE Trans. Ind. Electron., vol. PP, pp. $1-1,2010$.

[7] W. Wang, M. Cheng, W. Hua, W. Zhao, S. Ding, and Y. Zhu, "An improved stator flux observation strategy for direct torque controlled induction machine drive system," in Proc. Int. Conf. Electr. Mach. Syst., 2010, p. 5 pp.

[8] W. Wang, M. Cheng, W. Hua, W. Zhao, S. Ding, and Y. Zhu, "Hybrid modeling and applications of virtual metro systems," in Proc. IEEE Veh. Power Propul. Conf., 2010, pp. 1-5.

[9] B. Singh and D. Goyal, "Improved DSVM-DTC based current sensorless permanent magnet synchronous motor drive," in Proc. Int. Conf. Power Electron. Drive Syst., 2007, pp. 1354-1360.

[10] S. Morimoto, M. Sanada, and Y. Takeda, "High-performance current sensorless drive for synchronous motors with only low-resolution position sensor," in Proc. Conf. Rec. IAS Annu. Meet., 2002, pp. 2065-2072 vol.2063.
[11] T. Matsuo and T. A. Lipo, "Current sensorless field oriented control of synchronous reluctance motor," in Proc. Conf. Rec. IAS Annu. Meet., 1993, pp. 672-678 vol.671.

[12] A. Consoli, G. Scarcella, and A. Testa, "Speed and current sensorless field oriented induction motor drive operating at low stator frequencies," in Proc. Conf. Rec. IAS Annu. Meet., 2002, pp. 1679-1686 vol.1673.

[13] S. C. Chang and S. N. Yeh, "Current sensorless field-oriented control of induction motors," IEE Proc. Electr. Power Appl., vol. 143, pp. 492-500, 1996.

[14] F. Blaabjerg, J. K. Pedersen, U. Jaeger, and P. Thoegersen, "Single current sensor technique in the DC link of threephase PWM-VS inverters: a review and a novel solution," IEEE Trans. Ind. Appl., vol. 33, pp. 1241-1253, 1997.

[15] T. G. Habetler and D. M. Divan, "Control strategies for direct torque control using discrete pulse modulation," IEEE Trans. Ind. Appl., vol. 27, pp. 893-901, 1991.

[16] M. Bertoluzzo, G. Buja, and R. Menis, "Direct torque control of an induction motor using a single current sensor," IEEE Trans. Ind. Electron., vol. 53, pp. 778-784, 2006.

[17] H. Jung-Ik, "Current Prediction in Vector-Controlled PWM Inverters Using Single DC-Link Current Sensor," IEEE Trans. Ind. Electron., vol. 57, pp. 716-726, 2010.

[18] Y. Gu, F. Ni, D. Yang, and H. Liu, "Switching state phase shift method for three-phase current reconstruction with a single dc-link current sensor," IEEE Trans. Ind. Electron., vol. PP, pp. 1-1, 2011

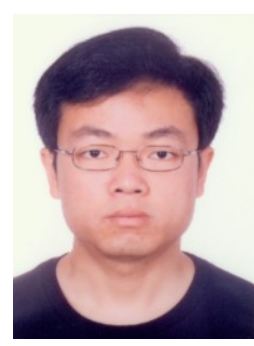

Wei Wang received the B.Sc. degree in electrical engineering from Nanjing University of Science \& Technology, Nanjing, China, in 2008. He is currently working toward the Ph.D. degree in electrical engineering at Southeast University, Nanjing, China. From October 2011 October 2012, he

was a joint

Ph.Dstudent with University of Lille 1, Lille, France. His research interests include electrical machine drives and rail transit.

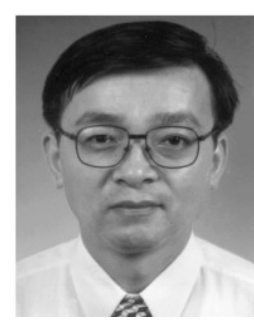

Ming Cheng received the B.Sc. and M.Sc. degrees from the Department of Electrical Engineering, Southeast University, China, in 1982 and 1987, respectively, and Ph.D. degree from the Department of Electrical and Electronic Engineering, The University of Hong Kong, Hong Kong, in 2001. Since 1987, he has been with Southeast University, where he is currently a professor in the School of Electrical Engineering and the Director of the Research Center for Wind Power Generation. His teaching and research interests include electrical machines, motor drives for electric vehicles and renewable energy generation. 
He has authored or coauthored over 200 technical papers and 4 books, and holds 45 patents in these areas. Prof. Cheng is a Fellow of IET and Senior Member of IEEE. He has served as chair and organizing committee member for many international conferences.

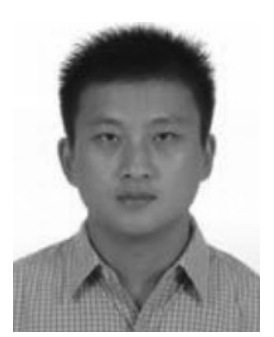

Wei Hua was born in Jiangsu, China, in 1978. He received the B.S. and Ph.D. degrees in electrical engineering from Southeast University, Nanjing, China, in 2001 and 2007, respectively. He is currently with Southeast University, where he is a professor and the Deputy Dean in the Department of Electrical Machines and Control. His research interests include design, analysis, and control of novel permanent magnet machines and switched reluctance machines. He has authored more than 100 published papers on those topics.

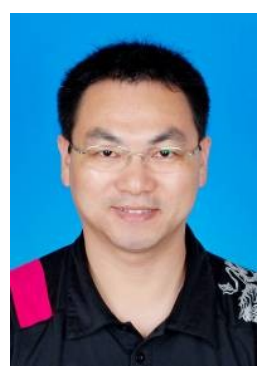

Shichuan Ding received the B.Sc. degree in electrical engineering from Anhui University, Hefei, China, in 2001 and the M.Sc. degree from USTC, Hefei, China, in 2006. He is currently working toward the Ph.D. degree in electrical engineering at Southeast University, Nanjing, China. His research interests include electrical machine drives and energy management in new energy vehicles.

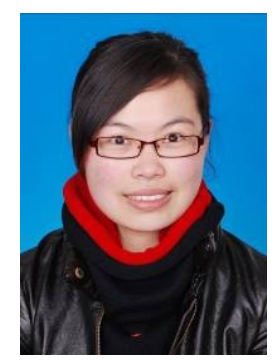

Ying Zhu received the B.Sc. degree in electrical engineering from Southeast University, Nanjing, China, in 2008. She is currently working toward the $\mathrm{Ph} . \mathrm{D}$. degree in electrical engineering at Southeast University, Nanjing, China. Her research interests include electrical machine drives and

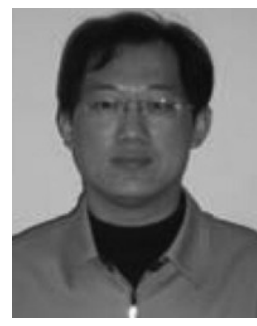

Wenxiang Zhao was born in Jilin, China, in 1976. He received the B.Sc. and M.Sc. degrees in electrical engineering from Jiangsu University, Zhenjiang, China, in 1999 and 2003, respectively, and the Ph.D. degree in electrical engineering at Southeast University, Nanjing, China, in 2010. Since 2003, he has been with Jiangsu University, where he is currently an associate professor in the School of Electrical and Information Engineering. His research interests include electric machine design, modeling, fault analysis, and intelligent control.

renewable energy. 